\author{
Editor \\ John A. Waldhausen, MD \\ Editorial Office-Room C4634 \\ The Journal of Thoracic and Cardiovascular Surgery \\ The Milton S. Hershey Medical Center \\ The Pennsylvania State University \\ PO Box 850, 500 University Dr \\ Hershey, PA 17033 \\ 717-531-6297 (telephone) \\ 717-531-4729 (fax) \\ jtcvs@aats.org (e-mail)
}

The Journal publishes peer-reviewed original articles on topics pertaining to thoracic and cardiovascular surgery. It is the official journal of The American Association for Thoracic Surgery and The Western Thoracic Surgical Association. All communications relating to the editorial management of the Journal should be sent to John A. Waldhausen, $\mathrm{MD}$, at the address given above.

\section{EDITORIAL POLICIES}

Statements and opinions expressed in the articles and communications herein are those of the author(s) and not necessarily those of the Editor, the publisher, or the Associations, and the Editor, the publisher, and the Associations disclaim any responsibility or liability for such materials. The Editor, the publisher, and the Associations do not guarantee, warrant, or endorse any product or service advertised in this publication, nor do they guarantee any claim made by the manufacturer of such product or service.

Review: All articles are reviewed by three or more referees. Acceptance is based upon significance, originality, and validity of the material presented. If the article is accepted for publication, editorial revisions may be made to aid clarity and understanding without altering the meaning.

Manuscripts: An original with one set of original figures and four copies of all material, including illustrations, should be submitted. Place author's name and page number in the upper right corner of each page. Use double spacing throughout. Manuscripts generally should not exceed twelve double-spaced, typewritten pages. Include a covering letter stating that the material has not been previously published or submitted elsewhere for publication. Identify in the letter the name, address, business and home telephone numbers, and fax number of the author to whom correspondence should be sent. GUIDELINES FOR PREPARATION OF A MANUSCRIPT ARE OUTLINED IN "NOTES FROM THE EDITORS" (J THORAC CARDIOVASC SURG 1996;112:209-20) AND SHOULD, IN GENERAL, BE FOLLOWED. Illustrations that are not accepted for publication may be returned to the authors. Illustrations for papers that have been accepted for publication will not be returned unless specifically requested by the author. Once a manuscript is accepted, the final version of the manuscript should be submitted on diskette, if possible, along with copies of the printout. The author accepts responsibility for the submitted diskette exactly matching the printout of the final version of the manuscript. Guidelines for submission of accepted manuscript on diskette will be sent to the author by the editorial office. After acceptance of the manuscript for publication, no author can be removed from the author list without the written permission of that author.

Copyright statement: According to the Copyright Act of 1976, all manuscripts must be accompanied by the copyright statement form that appears at the end of the Information for Authors section. This statement must be signed by all authors. Authors will be consulted, when possible, regarding republication of their material.

Conflict of interest: When the proposed publication concerns a device, such as an artificial valve or an instrument for measurement, as well as drugs, the author must enclose a statement (1) indicating that he or she has no financial or other interest in the manufacturer or distributor of the device or (2) explaining the nature of any relation between himself or herself and the manufacturer or distributor of the device. Other kinds of associations, such as consultancies, stock ownership, or other equity interests or patent-licensing arrangements, also must be disclosed.

Informed consent: Reports describing data obtained from research conducted in human subjects must contain a statement in the Methods section indicating approval by the institutional review board and affirmation that informed consent was obtained from each patient.

Humane animal care: All papers reporting experiments using animals must include a statement in the Methods section giving assurance that all animals have received humane care in compliance with the "Guide for the Care and Use of Laboratory Animals" prepared by the Institute of Laboratory Animal Resources and published by the National Institutes of Health (NIH Publication No. 86-23, revised 1985). Papers submitted from outside the United States must be in compliance with the guidelines established by their country's government or those of the National Institutes of Health.

Consultant statistician and statistical methods: All manuscripts with statistical analysis are required to undergo biostatistical review to insure adequate and appropriate study design, analysis, interpretation, and reporting. The Journal requires that these manuscripts be reviewed by a biostatistician prior to submission. The most appropriate way to involve a biostatistician is as a consultant or coauthor from the investigators' home institution or collaborative group. This individual must complete and sign the biostatistical guidelines, published twice yearly (January and July issues) in the 
Journal, All manuscripts will undergo further biostatistical review by the Journal after submission. Manuscripts will not be published or undergo final review without an acceptable rating by the biostatistical editorial staff. Additional information on statistical methods can be found in Uniform Requirements for Manuscripts Submitted to Biomedical Journals (Ann Intern Med 1997;126:36-47) and in Instructions for Authors, American Journal of Physiology.

Title page: Make the title concise. List affiliation and academic degrees of author(s). Restrict number of authors to those making material contributions. All sources of funding for the work should be acknowledged. Include where the work was done with the name, address, business and home telephone numbers, and fax number of individual to whom correspondence and reprint requests are to be addressed.

Abstract: On the first page of the manuscript, a structured abstract, limited to 250 words, should be provided. The structured abstract is to contain the following major headings: Objective(s); Methods; Results; and Conclusions. Objective is defined as the hypothesis or the purpose of the study. Methods is defined as the study design. Results includes the outcome of the study and statistical significance, if appropriate. Conclusions states the significance of the results. Please supply a word count and please do not use acronyms.

Ultramini-abstract: One to three sentences of no more than 50 words in all should be included as an ultramini-abstract, containing the essence of the manuscript, for inclusion immediately beneath the title of the paper in the table of contents.

Units of measurement. Measurements of length, height, weight, and volume should be reported in metric units (meter, kilogram, or liter) or their decimal multiples. Temperatures should be given in degrees Celsius. Blood pressures should be given in millimeters of mercury. All hematologic and clinical chemistry measurements should be reported in the metric system in terms of the International System of Units (SI). Alternative or non-SI units should also be added by the authors before publication. Please see "Uniform Requirements for Manuscripts Submitted to Biomedical Journals." Ann Intern Med 1997;126:36-47.

Abbreviations. Except for units of measurements, abbreviations are discouraged. The first time an abbreviation appears it should be preceded by the words for which it stands. No abbreviations are to be used in the title or abstract. Consult the following sources for acceptable standard abbreviations: (1) Scientific Style and Format: The Council of Biology Editors Manual for Authors, Editors, and Publishers (6th ed. New York: Cambridge University Press, 1994) and (2) Iverson, Cheryl, et al, editors. American Medical Association Manual of Style, 8th ed. Baltimore: Williams \& Wilkins, 1989.

References: References should be numbered serially in the text and listed, on a separate sheet, double-spaced, at the end of the paper in that order. Generally, references should not exceed 30 in number. Reference format should conform to that set forth in "Uniform Requirements for Manuscripts Submitted to Biomedical Joumals" (Ann Intern Med 1997;126:36-47). Journal abbreviations should conform to the style used in the Cumulated Index Medicus. Each reference should include:

For journals-authors' names and initials, title of article, journal name, date, volume number, and inclusive pages (list all authors when six or less; when seven or more, list six and add et al):

Sarris GE, Moore KA, Schroeder JS, Hunt SA, Fowler MB, Valantine HB, et al. Cardiac transplantation: the Stanford experience in the cyclosporine era. $\mathrm{J}$ Thorac Cardiovasc Surg 1994;108:241-52.

Morrow WR, Smith VC, Ehler WJ, VanDellen AF, Mullins CE. Balloon angioplasty with stent implantation in experimental coarctation of the aorta. Circulation 1994;89:2677-83.

\section{CHECKLIST}

_ Letter of submission

_ Copyright transfer letter

_ Original and four copies of article

_ Title page

_ Include title of article

_ Full name(s), academic degrees, and affiliations of author(s)

_ Author to whom correspondence is to be sent

_ Telephone (business and home) and fax numbers

_ Abstract (double-spaced)

_ Ultramini-abstract (50 words or less)

_ Article proper (double-spaced)

_ References (double-spaced) on a separate sheet

_ Tables

_ Legends (double-spaced) on a separate sheet

_ Illustrations, properly labeled (original and four copies)

_ Permission to reproduce published material or cite unpublished data

- Informed consent

_ Consultant statistician

Humane animal care

Brief clinical communications and letters to the Editor

(double-spaced)

_ Include covering letter

_Original and four copies of manuscript

_ Title page

_ Include title of article

_ Full name(s), academic degrees, and affiliations of author(s)

_ Author to whom correspondence is to be sent

_ Telephone (business and home) and fax numbers

_ Copyright transfer letter

For books-authors' names, chapter title, editor's name, book title, edition, city, publisher, date, and pages:

Kouchoukos NT, Wareing TH. Management of complications of aortic surgery. In: Waldhausen JA, Orringer MB, editors. Complications in cardiothoracic surgery. 1st ed. St Louis: Mosby-Year Book; 1991. p. 224-36.

Unpublished data and personal communications should not be listed as references. Authors are responsible for accuracy of their references.

Illustrations: Illustrations are scanned electronically. For best reproduction, screening, shading, and lettering on a dark background should be avoided. Detailed instructions are available from the editorial office. Digitized electronic files for illustrations may be submitted along with four copies of the printout on high-quality laser printer paper. For halftone drawings, histologic sections, electron microscopic data, echocardiograms, and color photographs, four sets of the glossy prints must be provided. Please put the sets of illustrations in separate envelopes.

Figures may be submitted in electronic format. All images should be at least 5 inches wide. Images should be provided in EPS or TIF format on Zip disk, CD, floppy, Jaz, or 3.5 MO. Macintosh or PC is acceptable. Graphics software such as Photoshop and Illustrator, not presentation software such as Powerpoint, CorelDraw, or Harvard Graphics, should be used in the creation of the art. Color images need to be CMYK, at least 300 
DPI, with a digital color proof, not a color laser print or color photocopy. Note: This proof will be used at press for color reproduction. Gray scale images should be at least $300 \mathrm{DPI}$ accompanied by a proof. Combinations of gray scale and line art should be at least 1200 DPI accompanied by a proof. Line art (black and white or color) should be at least 1200 DPI accompanied by a proof. Please include hardware and software information, in addition to the file names, with the disk.

Illustrations should be numbered in the order of their mention in the text, and marked lightly on the back with the author's name and an arrow to indicate top edge. A reasonable number of halftone illustrations will be reproduced free of cost to the author, but special arrangements must be made with the Editor for color plates, elaborate tables, or extra illustrations. All lettering must be done professionally and should be in proportion to the drawing, graph, or photograph. Do not send original art work, x-ray films, or ECG strips. Glossy print photographs, 3 by 4 inches (minimum) to 5 by 7 inches (maximum), with good black-and-white contrast or color balance are preferred. Consistency in size within the article is strongly preferred. Any special instructions regarding sizing should be clearly noted. Suitable legends should be typewritten, double-spaced, and listed on a separate sheet of paper and included at the end of the manuscript.

Tables: Tables should be self-explanatory and should supplement, not duplicate, the text. Type on pages separate from the text. Provide a brief title for each. Abbreviations used in tables should be defined at the bottom of the table.

Brief Communications: Authors are urged to submit brief clinical communications containing substantive information concerning clinical studies or a pertinent observation. These communications will be reviewed by the Editor as well as the appropriate Associate Editor. Four copies should be submitted. Such communications should be titled, double-spaced, and limited to three (3) typewritten, double-spaced pages with no more than two tables or figures and a brief bibliography (no more than five references). Brief clinical communications are retained and indexed in the Cumulated Index Medicus. The submitted brief communication must be accompanied by a signed copyright statement.

Letters to the Editor: Readers are encouraged to submit commentary on an article that has been published in the Journal, as well as other issues. Letters may be published together with a reply from the original author. If the original author does not respond, a notation indicating "Response declined" will be published. A covering letter should be submitted explaining any circumstances relevant to the "letter to the Editor." The letter itself should be titled and double-spaced, and four copies should be submitted. Substantive letters to the Editor are retained and indexed in the Cumulated Index Medicus. The submitted letter to the Editor must be accompanied by a signed copyright statement.

Reprints: Single reprints may be obtained from the author.

\section{THE JOURNAL OF THORACIC AND CARDIOVASCULAR SURGERY}

\section{COPYRIGHT AND CONFLICT OF INTEREST STATEMENT}

Must be signed by ALL authors

"The undersigned author(s) transfers all copyright ownership of the manuscript entitled

to Mosby, Inc, in the event the work is published. The undersigned author(s) warrants that the article is original; does not infringe upon any copyright or other proprietary right of any third party; is not under consideration by another publication; and has not been previously published. I (we) have no financial interest in the products presented in this work. If I (we) have a financial interest, it is disclosed on the attached sheet."

The corresponding author(s) must be named

$$
\text { (Type name) Signature }
$$

Each author's name must be typed underneath the signature.

Date: 